\title{
Enzyme-Mediated Enantioselective Hydrolysis of Aliphatic Dicarboxylic Acid Diesters
}

\author{
Yuta Igawa, Hironobu Ise, Sakina Ichinoseki, Fumie Maeda, Ai Kobayashi, Kazutsugu Matsumoto* \\ Department of Chemistry and Life Science, Meisei University, Tokyo, Japan \\ Email: ^mkazu@chem.meisei-u.ac.jp
}

How to cite this paper: Igawa, Y., Ise, H., Ichinoseki, S., Maeda, F., Kobayashi, A. and Matsumoto, K. (2017) Enzyme-Mediated Enantioselective Hydrolysis of Aliphatic Dicarboxylic Acid Diesters. Journal of Biomaterials and Nanobiotechnology, 8, 50-65. http://dx.doi.org/10.4236/jbnb.2017.81004

Received: December 6, 2016

Accepted: January 9, 2017

Published: January 12, 2017

Copyright $\odot 2017$ by authors and Scientific Research Publishing Inc. This work is licensed under the Creative Commons Attribution International License (CC BY 4.0).

http://creativecommons.org/licenses/by/4.0/

\section{Open Access}

\begin{abstract}
The enzyme-mediated highly enantioselective hydrolysis of aliphatic dicarboxylic acid diesters has been developed. The racemic diesters were easily prepared by the coupling of racemic alcohols with dicarboxylic anhydrides followed by esterification or with dicarboxylic acids. In the cases of bis(1-phenylethyl) glutarate and bis(1phenylethyl) adipate, the diesters which contained the $\mathrm{dl}$ - and meso-form diastereomers, were enantioselectively hydrolyzed by lipase from Candida antarctica (Novozym 435$)$ in buffer at $30^{\circ} \mathrm{C}$ to afford the almost optically pure $(R)$-1-phenylethanol. On the other hand, the following chemical hydrolysis of the remaining $(S, S)$-diesters and $(S)$-monoesters gave the $(S)$-alcohol. Finally, both enantiomers were stoichiometrically obtained in about $100 \%$ isolated yield based on the racemic diesters. The enzymatic reaction was also applicable for the preparation of several optically active alcohols. In some cases, both the reactivities and enantioselectivities were quite different from those in the case of the corresponding simple acetates.
\end{abstract}

\section{Keywords}

Adipate, Enzymatic Hydrolysis, Glutarate, Lipase, Optically Active Alcohols

\section{Introduction}

The enzyme-mediated kinetic resolution of racemic alcohols and esters is one of the attractive methods for the preparation of optically active compounds [1] [2] [3] [4]. In our previous study, we succeeded in the enantioselective hydrolysis of poly(ethylene glycol) (PEG; av MW 4600)-supported carbonates (1) using porcine pancreas lipase (PPL; Scheme 1) [5]. In this case, two molecules of the optically active 1-phenylethanol (2) could be released from one molecule of the substrate 1, and the theoretical total yield of 2 was up to $200 \%$. Unfortunately, the reactivity and enantioselectivitiy were moderate, and the amount of alcohols immobilized per gram of 1 (the loading capacity) was very low. This drawback is a limiting step for the preparative synthesis of the desirable enantiomer. 


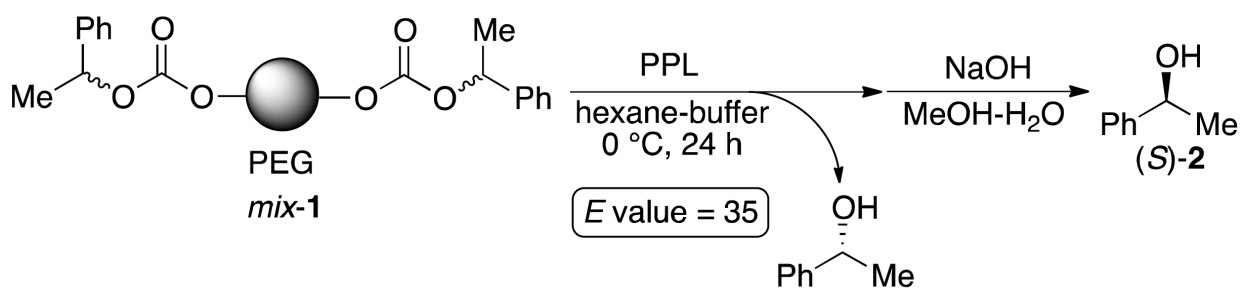

$(R)-2$

Scheme 1. Enzyme-mediated enantioselective hydrolysis of a PEG-supported substrate.

On the other hand, we also succeeded in the excellent enantioselective hydrolysis of aliphatic dicarboxylic acid monoesters 3 using lipase from Candida antarctica (Novozym 435; CAL-B), and the separation of the reaction products was achieved by a simple extraction procedure (Scheme 2) [6]. Then, we had noticed that the dicarboxylic acids would be a substitute for PEG spacer in Scheme 1, and the corresponding dicarboxylic acid diesters 4 could be a substrate for hydrolytic enzymes (Scheme 3). In this case, the gram-scale preparation of optically active compounds would be easy, because the molecular weight of the substrates would not be very high. Herein, we describe the enzyme-mediated enantioselective hydrolysis of aliphatic dicarboxylic acid diesters, and also report the methodical study of the substrate specificity. To the best of our knowledge, there have been only a very few reports on the enzyme-mediated enantioselective hydrolysis of diesters which release more than two equivalents of optically active alcohols [5] [7].

\section{Material and Methods}

\subsection{Materials}

Novozym 435 (L4777, >5.0 U/mg) was obtained from Sigma-Aldrich Co. LLC. E. Merck Kieselgel $60 \mathrm{~F}_{254}$ Art.5715 was used for analytical TLC. Preparative TLC was performed on E. Merck Kieselgel $60 \mathrm{~F}_{254}$ Art.5744. Column chromatography was performed with Silica Gel 60N (63 - 210 mm, Kanto Chemical Co., Inc.). All other chemicals were also obtained from commercial sources.

\subsection{Analytical Methods}

${ }^{1} \mathrm{H}(500$ or $300 \mathrm{MHz})$ and ${ }^{13} \mathrm{C}(125$ or $75 \mathrm{MHz})$ NMR spectra were measured on a JEOL JNM-500 or AL-300, respectively, with tetramethylsilane (TMS) as the internal standard. IR spectra were recorded with Shimadzu IR Prestige-21 spectrometers. Mass spectra were obtained with a JEOL EI/FAB mate BU25 Instrument by the EI method. Optical rotations were measured with a Jasco DIP-1030 polarimeter. HPLC data were obtained on Shimadzu LC- $10 \mathrm{AD}_{\mathrm{VP}}$, SPD- $10 \mathrm{~A}_{\mathrm{VP}}$, and $\mu 7$ Data Station (System Instruments Co., Ltd.) or Shimadzu LC-20AD, SPD-20A, and Smart Chrom (KYA technologies cooperation). GLC data were obtained on GL Sciences GC 353B, and $\mu 7$ Data Station (System Instruments Co., Ltd.).

\subsection{Preparation of the Substrates for the Enzymatic Reaction}

\subsubsection{Mix-Bis(1-Phenylethyl) Glutarate (4b)}

Under an argon atmosphere, 1-phenylethanol (( \pm$)-2,0.260 \mathrm{~mL}, 2.16 \mathrm{mmol})$ was added 


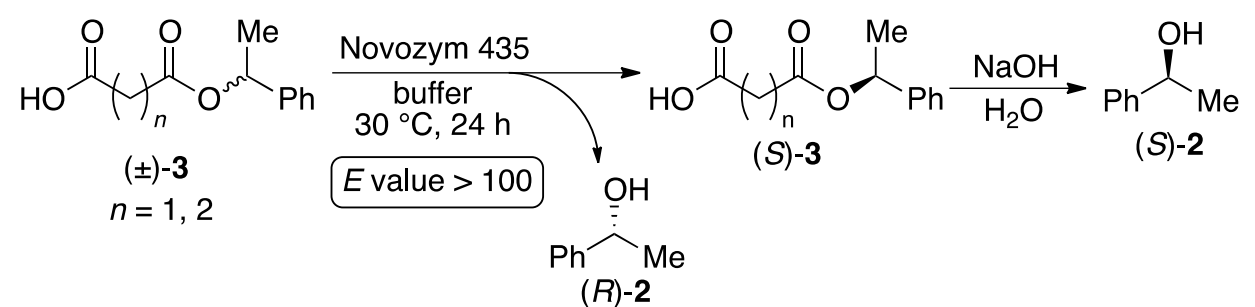

Scheme 2. Enzyme-mediated enantioselective hydrolysis of dicarboxylic monoesters.

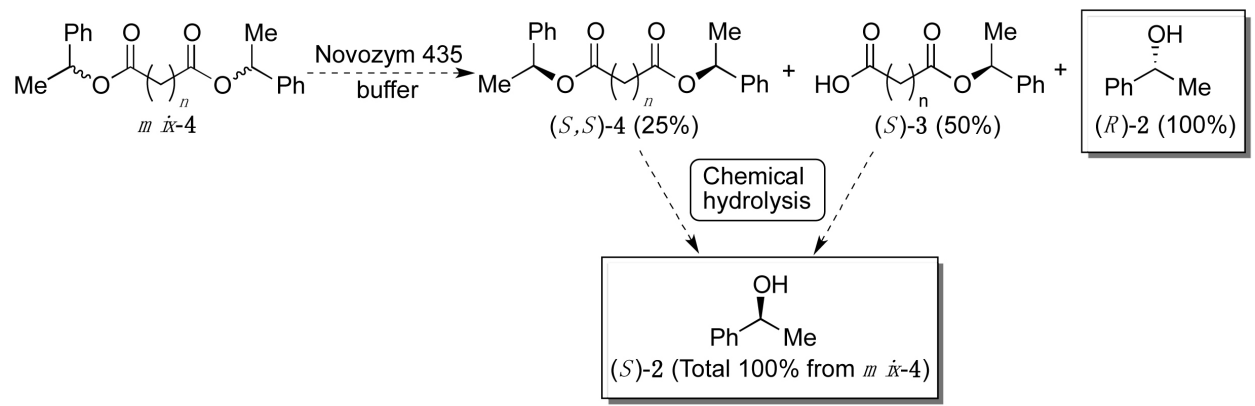

Scheme 3. Theoretical reaction of the enzyme-mediated enantioselective hydrolysis of racemic dicarboxylic acid diesters 4 (the numbers in parentheses are the theoretical \% yields from $m i x-4$ ).

to a solution of glutaric anhydride $(500.7 \mathrm{mg}, 4.388 \mathrm{mmol})$ in $\mathrm{CH}_{2} \mathrm{Cl}_{2}(10 \mathrm{~mL})$. To the solution DMAP $(1.047 \mathrm{~g}, 8.572 \mathrm{mmol})$ was added at $0^{\circ} \mathrm{C}$, and the mixture was stirred for $2 \mathrm{~h}$ at room temperature. After the mixture was washed with $2 \mathrm{M} \mathrm{HCl}$, the products were extracted with $\mathrm{CH}_{2} \mathrm{Cl}_{2}(\times 3)$, and dried over $\mathrm{Na}_{2} \mathrm{SO}_{4}$. After evaporation in vacuo, the residue was purified by column chromatography on silica gel (hexane/AcOEt $=4 / 1$ ) to give the ( \pm )-4-((1-phenylethoxy)carbonyl)butanoic acid (3b) as a colorless oil (527.9 mg, 79\%); IR (neat) 2980, 2936, 1732, 1709, 1495, 1452, 1375, 1287, 1246, 1207, 1155, 1063, 935, 762, $700 \mathrm{~cm}^{-1}$; ${ }^{1} \mathrm{H}$ NMR $\left(500 \mathrm{MHz}, \mathrm{CDCl}_{3}\right) \delta=1.54(\mathrm{~d}, J=6.5 \mathrm{~Hz}, 3 \mathrm{H}), 1.95$ (quintet, $J=7.5 \mathrm{~Hz}, 2 \mathrm{H}), 2.35-2.50(\mathrm{~m}, 4 \mathrm{H}), 5.89(\mathrm{q}, J=6.5 \mathrm{~Hz}, 1 \mathrm{H}), 7.25-7.41(\mathrm{~m}$, $5 \mathrm{H}) ;{ }^{13} \mathrm{C}$ NMR $\left(125 \mathrm{MHz}, \mathrm{CDCl}_{3}\right) \delta=19.8,22.2,32.9,33.4,72.5,126.0,127.9,128.5$, 141.5, 172.1, 179.0; MS m/z (EI, rel intensities) 236 ( $\left.\mathrm{M}^{+}, 11 \%\right), 121$ (100), 115 (77), 105 (100); HRMS m/z (EI) 236.1024 (calcd for $\mathrm{C}_{13} \mathrm{H}_{16} \mathrm{O}_{4}: 236.1049, \mathrm{M}^{+}$).

To a solution of $( \pm)-3 \mathrm{~b}(402.5 \mathrm{mg}, 1.704 \mathrm{mmol})$ and $( \pm)-2(0.200 \mathrm{~mL}, 1.66 \mathrm{mmol})$ in $\mathrm{CH}_{2} \mathrm{Cl}_{2}(5 \mathrm{~mL})$ were added DMAP $(383.6 \mathrm{mg}, 3.140 \mathrm{mmol})$ and DCC $(658.3 \mathrm{mg}, 3.190$ $\mathrm{mmol})$ at $0^{\circ} \mathrm{C}$, and the mixture was stirred overnight at room temperature. After the mixture was filtered through a celite pad using $\mathrm{CH}_{2} \mathrm{Cl}_{2}$, the filtrate was washed with 0.5 $\mathrm{M} \mathrm{HCl}(\mathrm{x} 2)$, and the organic layer was dried over $\mathrm{Na}_{2} \mathrm{SO}_{4}$. After evaporation in vacuo, the residue was purified by column chromatography on silica gel (hexane/AcOEt $=8 / 1$ ) to give $m i x-4 b$ as a colorless oil (434.5 mg, 75\%); IR (neat) 2978, 2931, 2360, 1734, $1450,1375,1250,1173,1063,762,698 \mathrm{~cm}^{-1} ;{ }^{1} \mathrm{H} \mathrm{NMR}\left(300 \mathrm{MHz}, \mathrm{CDCl}_{3}\right) \delta=1.52(\mathrm{~d}, J=$ $6.5 \mathrm{~Hz}, 6 \mathrm{H}$ ), 1.94 (quintet, $J=7.5 \mathrm{~Hz}, 2 \mathrm{H}$ ), $2.37(\mathrm{t}, J=7.5 \mathrm{~Hz}, 4 \mathrm{H}), 5.88(\mathrm{q}, J=6.5 \mathrm{~Hz}$, 2H), $7.21-7.38(\mathrm{~m}, 10 \mathrm{H}) ;{ }^{13} \mathrm{C}$ NMR $\left(125 \mathrm{MHz}, \mathrm{CDCl}_{3}\right) \delta=20.1,22.3,33.5,72.3,126.0$, 127.9, 128.5, 141.6, 172.2; MS m/z (EI, rel intensities) 341 ( $\left.\mathrm{M}^{+}, 6.5 \%\right), 235$ (100), 120 (100), 105 (100); HRMS m/z (EI) 341.1754 (calcd for $\mathrm{C}_{21} \mathrm{H}_{25} \mathrm{O}_{4}: 341.1753, \mathrm{M}^{+}+\mathrm{H}$ ).

The compound $\mathbf{4 b}$ is a $1: 1$ mixture of $d l-$ and meso-form diastereomers. The ratio 
was determined by HPLC analysis using CHIRALCEL AS-H (Daicel Chemical Industries, Ltd.): eluent, hexane/2-propanol = 95/5; flow rate, $0.5 \mathrm{~mL} / \mathrm{min}$; $254 \mathrm{~nm}$; temperature, $25^{\circ} \mathrm{C}$; retention time, $12.2(R, R)$ and 12.8 [meso and $\left.(S, S)\right] \mathrm{min}$.

Other substrates $4 \mathrm{a}, \mathbf{1 8 b}, \mathbf{1 9 b}, \mathbf{2 0 b}, \mathbf{2 1 b}, \mathbf{2 2 b}$ and $\mathbf{2 3 b}$ were synthesized by the same procedure.

\subsubsection{Mix-Bis(1-Phenylethyl) Succinate (4a)}

Yield 73\% from ( \pm )-2 in 2 steps (a colorless oil); IR (neat) 2980, 2931, 2363, 1734, 1456, 1450, 1375, 1207, 1159, 1062, 862, 761, $698 \mathrm{~cm}^{-1}$; ${ }^{1} \mathrm{H}$ NMR $\left(500 \mathrm{MHz}, \mathrm{CDCl}_{3}\right) \delta=1.51$ $(\mathrm{d}, J=7.0 \mathrm{~Hz})$ and $1.52(\mathrm{~d}, J=6.5 \mathrm{~Hz})(6 \mathrm{H}), 2.57-2.75(\mathrm{~m}, 4 \mathrm{H}), 5.89(\mathrm{q}, J=6.5 \mathrm{~Hz}$, 2H), 7.25 - $7.38(\mathrm{~m}, 10 \mathrm{H}) ;{ }^{13} \mathrm{C} \mathrm{NMR}\left(75 \mathrm{MHz}, \mathrm{CDCl}_{3}\right) \delta=22.1,22.2,29.4,29.5,72.7$, 126.0, 126.1, 127.9, 128.5, 141.5, 171.4; MS m/z (EI, rel intensities) $354\left(\mathrm{M}^{+}, 0.8 \%\right), 221$ (100), 149 (100), 121 (100), 105 (100); HRMS m/z (EI) 326.1510 (calcd for $\mathrm{C}_{20} \mathrm{H}_{22} \mathrm{O}_{4}$ : 326.1518, $\mathrm{M}^{+}$).

\subsubsection{Mix-Bis(1-Phenylpropyl) Glutarate (18b)}

Yield 90\% from ( \pm )-6 in 2 steps (a colorless oil); IR (neat) 2972, 2936, 2876, 1734, 1456, $1381,1246,1171,1084,964,756,700 \mathrm{~cm}^{-1} ;{ }^{1} \mathrm{H} \mathrm{NMR}\left(300 \mathrm{MHz}, \mathrm{CDCl}_{3}\right) \delta=0.87(\mathrm{t}, J=$ $7.5 \mathrm{~Hz}, 6 \mathrm{H}), 1.65-2.02(\mathrm{~m}, 6 \mathrm{H}), 2.30-2.46(\mathrm{~m}, 4 \mathrm{H}), 5.66(\mathrm{t}, J=7.0 \mathrm{~Hz}, 2 \mathrm{H}), 7.20-7.41$ $(\mathrm{m}, 10 \mathrm{H}) ;{ }^{13} \mathrm{C} \mathrm{NMR}\left(125 \mathrm{MHz}, \mathrm{CDCl}_{3}\right) \delta=9.9,20.2,29.3,33.5,77.4,126.5,127.8,128.4$, 140.5, 172.2; MS m/z (EI, rel intensities) $369\left(\mathrm{M}^{+}+\mathrm{H}, 1.5 \%,\right), 368\left(\mathrm{M}^{+}, 0.5\right), 249(100)$, 233 (4.6), 135 (100), 119 (100); HRMS m/z (EI) 368.2013 (calcd for $\mathrm{C}_{23} \mathrm{H}_{28} \mathrm{O}_{4}$ : 382.2144, $\mathrm{M}^{+}$.

\subsubsection{Mix-Bis(1-Phenylpropan-2-yl) Glutarate (19b)}

Yield 89\% from $( \pm)-7$ in 2 steps (a colorless oil); IR (neat) 2976, 2932, 1719, 1491, 1452, $1377,1251,1177,1134,1059,746,700 \mathrm{~cm}^{-1} ;{ }^{1} \mathrm{H}$ NMR $\left(500 \mathrm{MHz}, \mathrm{CDCl}_{3}\right) \delta=1.215(\mathrm{~d}, J$ $=6.5 \mathrm{~Hz})$ and $1.218(\mathrm{~d}, J=6.5 \mathrm{~Hz})(6 \mathrm{H}), 1.81\left(\mathrm{tt}, J_{1}=J_{2}=7.5 \mathrm{~Hz}, 2 \mathrm{H}\right), 2.18-2.25(\mathrm{~m}$, $4 \mathrm{H}), 2.75\left(\mathrm{dd}, J_{1}=6.5 \mathrm{~Hz}, J_{2}=13.5 \mathrm{~Hz}, 2 \mathrm{H}\right), 2.90\left(\mathrm{ddd}, J_{1}=1.5 \mathrm{~Hz}, J_{2}=6.5 \mathrm{~Hz}, J_{3}=13.5\right.$ $\mathrm{Hz} 2 \mathrm{H}), 5.12\left(\mathrm{tq}, J_{1}=J_{2}=6.5 \mathrm{~Hz}, 2 \mathrm{H}\right), 7.16-7.30(\mathrm{~m}, 10 \mathrm{H}) ;{ }^{13} \mathrm{C}$ NMR $(125 \mathrm{MHz}$, $\left.\mathrm{CDCl}_{3}\right) \delta=19.7,20.2,33.6,42.4,71.6,126.6,128.4,129.5,137.7,172.5 ; \mathrm{MS} \mathrm{m} / \mathrm{z}$ (EI, rel intensities) $369\left(\mathrm{M}^{+}+\mathrm{H}, 29 \%\right), 368\left(\mathrm{M}^{+}, 1.0\right), 251$ (100), 233 (100), 135 (79), 119 (100); HRMS m/z (EI) 368.1946 (calcd for $\mathrm{C}_{23} \mathrm{H}_{28} \mathrm{O}_{4}: 368.1988, \mathrm{M}^{+}$).

\subsubsection{Mix-Bis(1-(Naphthalen-2-yl)Ethyl) Glutarate (20b)}

Yield 53\% from ( \pm )-8 in 2 steps (a colorless solid); IR (KBr) 2927, 1734, 1236, 1171, 1066, 908, 777, $733 \mathrm{~cm}^{-1}$; ${ }^{1} \mathrm{H} \operatorname{NMR}\left(300 \mathrm{MHz}, \mathrm{CDCl}_{3}\right) \delta=1.679(\mathrm{~d}, J=6.5 \mathrm{~Hz})$ and $1.683(\mathrm{~d}, J=6.5 \mathrm{~Hz})(6 \mathrm{H}), 1.92-2.06(\mathrm{~m}, 2 \mathrm{H}), 2.33-2.52(\mathrm{~m}, 4 \mathrm{H}), 6.64(\mathrm{q}, J=6.5 \mathrm{~Hz}$, 2H), $7.36-7.60(\mathrm{~m}, 8 \mathrm{H}), 7.78(\mathrm{~d}, J=8.0 \mathrm{~Hz}, 1 \mathrm{H}), 7.85(\mathrm{~d}, J=7.0 \mathrm{~Hz}, 1 \mathrm{H}), 8.06(\mathrm{~d}, J=$ $8.0 \mathrm{~Hz}, 1 \mathrm{H}) ;{ }^{13} \mathrm{C} \mathrm{NMR}\left(125 \mathrm{MHz}, \mathrm{CDCl}_{3}\right) \delta=20.2,21.7,33.6,69.5,123.1,125.4,125.7$, $126.3,128.4,128.9,130.2,133.8,137.4,172.2 ; \mathrm{MS} \mathrm{m} / \mathrm{z}$ (EI, rel intensities) $440\left(\mathrm{M}^{+}\right.$, 23\%), 285 (1.2), 171 (100), 155 (100), 115 (27); HRMS m/z (EI) 440.1990 (calcd for $\left.\mathrm{C}_{29} \mathrm{H}_{28} \mathrm{O}_{4}: 440.1988, \mathrm{M}^{+}\right)$.

\subsection{6. $M i x$-Bis(1-(Naphthalen-1-yl)Ethyl) Glutarate (21b)}

Yield 91\% from ( \pm )-9 in 2 steps (a colorless oil); IR (neat) 2980, 2931, 1722, 1373, 1277, 
1171, 1049, 824, $746 \mathrm{~cm}^{-1} ;{ }^{1} \mathrm{H} \operatorname{NMR}\left(300 \mathrm{MHz}, \mathrm{CDCl}_{3}\right) \delta=1.603(\mathrm{~d}, J=6.5 \mathrm{~Hz})$ and $1.609(\mathrm{~d}, J=6.5 \mathrm{~Hz})(6 \mathrm{H}), 1.91-2.07(\mathrm{~m}, 2 \mathrm{H}), 2.41(\mathrm{t}, J=7.0 \mathrm{~Hz}, 4 \mathrm{H}), 6.05\left(\mathrm{dq}, J_{1}=1.5\right.$ $\left.\mathrm{Hz}, J_{2}=6.5 \mathrm{~Hz}, 2 \mathrm{H}\right), 7.39-7.55(\mathrm{~m}, 6 \mathrm{H}), 7.75-7.90(\mathrm{~m}, 8 \mathrm{H}) ;{ }^{13} \mathrm{C} \mathrm{NMR}(125 \mathrm{MHz}$, $\left.\mathrm{CDCl}_{3}\right) \delta=20.2,21.7,33.6,69.5,123.1,125.4,125.7,126.3,128.4,128.9,130.2,133.8$, 137.4, 172.2; MS m/z (EI, rel intensities) $440\left(\mathrm{M}^{+}, 23 \%\right), 285$ (1.2), 171 (100), 155 (100), 115 (27); HRMS m/z (EI) 440.1983 (calcd for $\mathrm{C}_{29} \mathrm{H}_{28} \mathrm{O}_{4}: 440.1988, \mathrm{M}^{+}$).

\subsubsection{Mix-Bis(4-Phenylbutan-2-yl) Glutarate (22b)}

Yield 27\% from ( \pm )-10 in 2 steps (a colorless oil); IR (neat) 2974, 2932, 2361, 2344, $1732,1454,1377,1250,1179,1130,1051,748,698 \mathrm{~cm}^{-1} ;{ }^{1} \mathrm{H} \mathrm{NMR}\left(300 \mathrm{MHz}, \mathrm{CDCl}_{3}\right)$ $\delta=1.25(\mathrm{~d}, J=6.0 \mathrm{~Hz}, 6 \mathrm{H}), 1.71-2.05(\mathrm{~m}, 4 \mathrm{H}), 2.35(\mathrm{t}, J=7.5 \mathrm{~Hz}, 4 \mathrm{H}), 2.50-2.77(\mathrm{~m}$, $4 \mathrm{H}), 4.95\left(\mathrm{tq}, J_{1}=J_{2}=6.0 \mathrm{~Hz}, 2 \mathrm{H}\right), 7.09-7.22(\mathrm{~m}, 6 \mathrm{H}), 7.22-7.35(\mathrm{~m}, 4 \mathrm{H}) ;{ }^{13} \mathrm{C} \mathrm{NMR}$ $\left(125 \mathrm{MHz} \mathrm{CDCl}_{3}\right) \delta=20.2,29.8,31.9,37.6,70.6$ and 70.8, 125.9 and 126.0, 128.4, 128.5, 141.6, 172.7; MS m/z (EI, rel intensities) $396\left(\mathrm{M}^{+}, 100 \%\right), 291$ (4.8), 273 (81), 265 (18), 247 (57), 177 (38), 149 (64), 133 (100), 115 (100), 105 (100); HRMS m/z (EI) 396.2301 (calcd for $\mathrm{C}_{25} \mathrm{H}_{32} \mathrm{O}_{4}: 396.2301, \mathrm{M}^{+}$).

\subsubsection{Mix-Bis(4-(Benzyloxy)Butan-2-yl) Glutarate (23b)}

Yield 40\% from $( \pm$ )-11 in 2 steps (a colorless oil); IR (neat) 2976, 2934, 2862, 1728, $1454,1377,1252,1201,1028,739,698 \mathrm{~cm}^{-1}$; ${ }^{1} \mathrm{H}$ NMR $\left(500 \mathrm{MHz}, \mathrm{CDCl}_{3}\right) \delta=1.23(\mathrm{~d}, J=$ $6.0 \mathrm{~Hz}, 6 \mathrm{H}), 1.72-2.00(\mathrm{~m}, 6 \mathrm{H}), 2.27(\mathrm{t}, J=7.5 \mathrm{~Hz}, 2 \mathrm{H}), 3.43-3.53(\mathrm{~m}, 4 \mathrm{H}), 4.466(\mathrm{~d}, J$ $=12.0 \mathrm{~Hz}, 2 \mathrm{H}), 4.471(\mathrm{~d}, J=12.0 \mathrm{~Hz}, 2 \mathrm{H}), 5.04-5.14(\mathrm{~m}, 2 \mathrm{H}), 7.24-7.38(\mathrm{~m}, 10 \mathrm{H}) ;{ }^{13} \mathrm{C}$ $\operatorname{NMR}\left(125 \mathrm{MHz}, \mathrm{CDCl}_{3}\right) \delta=20.4,33.7,36.1,66.6,68.6,73.1,127.7,127.8,128.5,138.4$, 172.6; MS m/z (EI, rel intensities) $456\left(\mathrm{M}^{+}, 6 \%\right), 365$ (74), 349 (42), 277 (100), 179, (85), 163 (100), 121 (100), 114 (100), 107 (100); HRMS m/z (EI) 456.2509 (calcd for $\left.\mathrm{C}_{27} \mathrm{H}_{36} \mathrm{O}_{4}: 456.2512, \mathrm{M}^{+}\right)$.

\subsubsection{Mix-Bis(1-Phenylethyl) Adipate (4c)}

To a solution of adipic acid $(1.00 \mathrm{~g}, 6.84 \mathrm{mmol})$ in $\mathrm{CH}_{2} \mathrm{Cl}_{2}(3 \mathrm{~mL})$ were added $( \pm)-2$ (2.50 mL, $20.8 \mathrm{mmol})$, a solution of DMAP (1.67 g, $13.7 \mathrm{mmol})$ in $\mathrm{CH}_{2} \mathrm{Cl}_{2}(9 \mathrm{~mL})$ and a solution of DCC $(3.53 \mathrm{~g}, 17.1 \mathrm{mmol})$ in $\mathrm{CH}_{2} \mathrm{Cl}_{2}(9 \mathrm{~mL})$ at $0^{\circ} \mathrm{C}$, and the mixture was stirred overnight at room temperature. After the mixture was filtered through a celite pad using $\mathrm{CH}_{2} \mathrm{Cl}_{2}$, the filtrate was washed with $0.5 \mathrm{M} \mathrm{HCl}$ (x2), and the organic layer was dried over $\mathrm{Na}_{2} \mathrm{SO}_{4}$. After evaporation in vacuo, the residue was purified by column chromatography on silica gel (hexane/AcOEt $=4 / 1$ ) to give mix-4c as a colorless oil (2.20 g, 90\%); IR (neat) 2978, 2931, 2361, 1734, 1452, 1375, 1244, 1170, 1064, 1029, 761, $698 \mathrm{~cm}^{-1}$; ${ }^{1} \mathrm{H}$ NMR $\left(300 \mathrm{MHz}, \mathrm{CDCl}_{3}\right) \delta=1.51(\mathrm{~d}, J=6.5 \mathrm{~Hz}, 6 \mathrm{H}), 1.56-1.74(\mathrm{~m}, 4 \mathrm{H})$, $2.22-2.42(\mathrm{~m}, 4 \mathrm{H}), 5.86(\mathrm{q}, J=6.5 \mathrm{~Hz}, 2 \mathrm{H}), 7.21-7.39(\mathrm{~m}, 10 \mathrm{H}) ;{ }^{13} \mathrm{C} \mathrm{NMR}(75 \mathrm{MHz}$, $\left.\mathrm{CDCl}_{3}\right) \delta=22.2,24.3,34.2,72.5,126.0,127.8,128.5,141.7,172.5 ; \mathrm{MS} \mathrm{m} / \mathrm{z}$ (EI, rel intensities) 354 (M+1 1.0\%), 249 (100), 233 (17), 121 (100); HRMS m/z (EI) 354.1816 (calcd for $\mathrm{C}_{22} \mathrm{H}_{26} \mathrm{O}_{4}: 354.1831, \mathrm{M}^{+}$).

The compound $4 \mathrm{c}$ is a $1: 1$ mixture of $d l$ - and meso-form diastereomers. The ratio was determined by HPLC analysis using CHIRALCEL OD-H (Daicel Chemical Industries, Ltd.): eluent, hexane/2-propanol = 95/5; flow rate, $0.5 \mathrm{~mL} / \mathrm{min}$; $254 \mathrm{~nm}$; temperature, $25^{\circ} \mathrm{C}$; retention time, $17.0(R, R), 18.4$ (meso), and $19.8(S, S) \mathrm{min}$. 
Other substrates $4 d-f, 18 c, 19 c, 20 c, 21 c, 22 c$ and $23 c$ were synthesized by the same procedure.

\subsubsection{Mix-Bis(1-Phenylethyl) Heptanedioate (4d)}

Yield 58\% from pimelic acid (a colorless oil); IR (neat) 2978, 2933, 2363, 1734, 1452, 1373, 1250, 1172, 1065, 1030, 762, $698 \mathrm{~cm}^{-1}$; ${ }^{1} \mathrm{H}$ NMR (500 MHz, $\left.\mathrm{CDCl}_{3}\right) \delta=1.24-1.33$ $(\mathrm{m}, 2 \mathrm{H}), 1.52(\mathrm{~d}, J=6.5 \mathrm{~Hz}, 6 \mathrm{H}), 1.58-1.67(\mathrm{~m}, 4 \mathrm{H}), 2.30(\mathrm{t}, J=6.5 \mathrm{~Hz}, 2 \mathrm{H}), 2.31(\mathrm{t}, J=$ $7.5 \mathrm{~Hz}, 2 \mathrm{H}), 5.88(\mathrm{q}, J=6.5 \mathrm{~Hz}, 2 \mathrm{H}), 7.24-7.38(\mathrm{~m}, 10 \mathrm{H}) ;{ }^{13} \mathrm{C}$ NMR $\left(75 \mathrm{MHz}, \mathrm{CDCl}_{3}\right)$ $\delta=22.2,24.5,28.5,34.3,72.1,126.0,127.8,128.5,141.7,172.8 ; \mathrm{MS} \mathrm{m} / \mathrm{z}$ (EI, rel intensities) $369\left(\mathrm{M}^{+}+\mathrm{H}, 1.1 \%\right), 368\left(\mathrm{M}^{+}, 1.0\right), 263$ (100), 149 (5.5), 143 (100), 121 (100); HRMS m/z (EI) 369.2085 (calcd for $\mathrm{C}_{23} \mathrm{H}_{29} \mathrm{O}_{4}: 369.2066, \mathrm{M}^{+}+\mathrm{H}$ ).

\subsubsection{Mix-Bis(1-Phenylethyl) Octanedioate (4e)}

Yield 84\% from suberic acid (a colorless oil); IR (neat) 2978, 2934, 2361, 1734, 1450, 1248, 1171, 1065, 1030, 762, $698 \mathrm{~cm}^{-1}$; ${ }^{1} \mathrm{H}$ NMR $\left(500 \mathrm{MHz}, \mathrm{CDCl}_{3}\right) \delta=1.24-1.33(\mathrm{~m}$, $4 \mathrm{H}), 1.53(\mathrm{~d}, J=6.5 \mathrm{~Hz}, 6 \mathrm{H}), 1.55-1.64(\mathrm{~m}, 4 \mathrm{H}), 2.297(\mathrm{t}, J=7.5 \mathrm{~Hz}, 2 \mathrm{H}), 2.302(\mathrm{t}, J=$ $7.5 \mathrm{~Hz}, 2 \mathrm{H}), 5.88(\mathrm{q}, J=6.5 \mathrm{~Hz}, 2 \mathrm{H}), 7.24-7.31(\mathrm{~m}, 2 \mathrm{H}), 7.31-7.39(\mathrm{~m}, 8 \mathrm{H}) ;{ }^{13} \mathrm{C}$ NMR $\left(75 \mathrm{MHz}, \mathrm{CDCl}_{3}\right) \delta=22.2,24.7,28.6,34.4,72.0,126.0,127.8,128.4,141.8,172.9$; MS $\mathrm{m} / \mathrm{z}$ (EI, rel intensities) $383\left(\mathrm{M}^{+}+\mathrm{H}, 1.5 \%\right), 277$ (100), 157 (100), 139 (91), 121 (100), 105 (100); HRMS m/z (EI) 383.2220 (calcd for $\mathrm{C}_{24} \mathrm{H}_{31} \mathrm{O}_{4}: 383.2222, \mathrm{M}^{+}+\mathrm{H}$ ).

\subsubsection{Mix-Bis(1-Phenylethyl) Decanedioate (4f)}

Yield 74\% from sebacic acid (a colorless oil); IR (neat) 2930, 2855, 2361, 1734, 1452, 1373, 1244, 1170, 1065, 1030, 762, $698 \mathrm{~cm}^{-1}$; ${ }^{1} \mathrm{H}$ NMR (300 MHz, $\left.\mathrm{CDCl}_{3}\right) \delta=1.18-1.34$ $(\mathrm{m}, 8 \mathrm{H}), 1.52(\mathrm{~d}, J=7.0 \mathrm{~Hz}, 6 \mathrm{H}), 1.52-1.68(\mathrm{~m}, 4 \mathrm{H}), 2.31(\mathrm{t}, J=7.5 \mathrm{~Hz}, 3 \mathrm{H}), 5.88(\mathrm{q}$, $J=6.5 \mathrm{~Hz}, 2 \mathrm{H}), 7.23-7.38(\mathrm{~m}, 10 \mathrm{H}) ;{ }^{13} \mathrm{C} \mathrm{NMR}\left(75 \mathrm{MHz}, \mathrm{CDCl}_{3}\right) \delta=22.2,24.9,28.97$, 29.01, 34.6, 72.0, 126.0, 127.8, 128.4, 141.8, 173.1; MS m/z (EI, rel intensities) $411\left(\mathrm{M}^{+}+\right.$ H, 0.9\%), 305 (100), 287 (12), 185 (100), 139 (100), 121 (100), 105 (100); HRMS m/z (EI) 411.2531 (calcd for $\left.\mathrm{C}_{26} \mathrm{H}_{35} \mathrm{O}_{4}: 411.2535, \mathrm{M}^{+}+\mathrm{H}\right)$.

\subsubsection{Mix-Bis(1-Phenylpropyl) Adipate (18c)}

Yield 84\% from adipic acid (a colorless oil); IR (neat) 2968, 2936, 2876, 1732, 1494, 1454, 1381, 1240, 1168, 1084, 968, 912, 756, $700 \mathrm{~cm}^{-1}$; ${ }^{1} \mathrm{H}$ NMR $\left(300 \mathrm{MHz}, \mathrm{CDCl}_{3}\right) \delta=$ $0.87(\mathrm{t}, J=7.5 \mathrm{~Hz}, 6 \mathrm{H}), 1.56-1.58(\mathrm{~m}, 4 \mathrm{H}), 1.59-2.00(\mathrm{~m}, 4 \mathrm{H}), 2.25-2.43(\mathrm{~m}, 4 \mathrm{H})$, $5.65(\mathrm{t}, J=7.0 \mathrm{~Hz}, 2 \mathrm{H}), 7.22-7.41(\mathrm{~m}, 10 \mathrm{H}) ;{ }^{13} \mathrm{C} \mathrm{NMR}\left(125 \mathrm{MHz}, \mathrm{CDCl}_{3}\right) \delta=9.9,24.4$, 29.3, 34.1, 126.5, 127.8, 128.4, 140.6, 172.6; MS m/z (EI, rel intensities) $382\left(\mathrm{M}^{+}, 1.0\right)$, 263 (100), 235 (100), 135 (100), 129 (100), 119 (100); HRMS m/z (EI) 382.2107 (calcd for $\left.\mathrm{C}_{24} \mathrm{H}_{30} \mathrm{O}_{4}: 382.2144, \mathrm{M}^{+}\right)$.

\subsubsection{Mix-Bis(1-Phenylpropan-2-yl) Adipate (19c)}

Yield 72\% from adipic acid (a colorless oil); IR (neat) 2976, 2932, 2369, 1732, 1452, $1375,1248,1175,1132,1076,1059,746,700 \mathrm{~cm}^{-1} ;{ }^{1} \mathrm{H}$ NMR $\left(500 \mathrm{MHz}, \mathrm{CDCl}_{3}\right) \delta=1.21$ $(\mathrm{d}, J=6.0 \mathrm{~Hz}, 6 \mathrm{H}), 1.44-1.55(\mathrm{~m}, 4 \mathrm{H}), 2.16-2.25(\mathrm{~m}, 4 \mathrm{H}), 2.75\left(\mathrm{dd}, J_{1}=6.5 \mathrm{~Hz}, J_{2}=\right.$ $13.5 \mathrm{~Hz}, 2 \mathrm{H}), 2.90\left(\mathrm{dd}, J_{1}=7.0 \mathrm{~Hz}, J_{2}=13.5 \mathrm{~Hz}, 2 \mathrm{H}\right), 5.12\left(\mathrm{qt}, J_{1}=J_{2}=6.5 \mathrm{~Hz}, 2 \mathrm{H}\right), 7.15$ - $7.31(\mathrm{~m}, 10 \mathrm{H}) ;{ }^{13} \mathrm{C} \mathrm{NMR}\left(125 \mathrm{MHz}, \mathrm{CDCl}_{3}\right) \delta=19.7,24.4,34.3,42.4,71.5,126.6$, 128.4, 129.5, 137.7, 172.9; MS m/z (EI, rel intensities) $383\left(\mathrm{M}^{+}+\mathrm{H}, 13 \%\right), 382\left(\mathrm{M}^{+}, 1.1\right)$, 
265 (100), 247 (100), 135 (18), 129 (100), 119 (100); HRMS m/z (EI) 382.2099 (calcd for $\left.\mathrm{C}_{24} \mathrm{H}_{30} \mathrm{O}_{4}: 382.2144, \mathrm{M}^{+}\right)$.

\subsubsection{Mix-Bis(2-(Naphthalen-2-yl)Ethyl) Adipate (20c)}

Yield 51\% from adipic acid (a colorless solid); IR (KBr) 2934, 1721, 1510, 1375, 1256, 1167, 1053, 804, $781 \mathrm{~cm}^{-1}$; ${ }^{1} \mathrm{H}$ NMR $\left(300 \mathrm{MHz}, \mathrm{CDCl}_{3}\right) \delta=1.68(\mathrm{~d}, J=6.5 \mathrm{~Hz}, 2 \mathrm{H}), 1.82$ $2.00(\mathrm{~m}, 4 \mathrm{H}), 2.30-2.44(\mathrm{~m}, 4 \mathrm{H}), 6.64(\mathrm{q}, J=6.5 \mathrm{~Hz}, 2 \mathrm{H}), 7.38-7.55(\mathrm{~m}, 6 \mathrm{H}), 7.56(\mathrm{~d}, J$ $=7.5 \mathrm{~Hz}, 1 \mathrm{H}), 7.78(\mathrm{~d}, J=8.5 \mathrm{~Hz}, 1 \mathrm{H}), 7.86(\mathrm{~d}, J=7.5 \mathrm{~Hz}, 1 \mathrm{H}), 8.06(\mathrm{~d}, J=8.0 \mathrm{~Hz}, 1 \mathrm{H})$; ${ }^{13} \mathrm{C} \mathrm{NMR}\left(125 \mathrm{MHz}, \mathrm{CDCl}_{3}\right) \delta=21.8,24.5,34.3,69.5,123.3,125.4,125.8,126.4,128.5$, 129.0, 130.3, 133.9, 137.5, 172.7; MS m/z (EI, rel intensities) 454 ( $\left.\mathrm{M}^{+}, 43 \%\right), 299$ (1.3), 171 (100), 155 (100), 129 (64); HRMS m/z (EI) 454.2144 (calcd for $\mathrm{C}_{30} \mathrm{H}_{30} \mathrm{O}_{4}: 454.2144$, $\left.\mathrm{M}^{+}\right)$.

\subsubsection{Mix-Bis(1-(Naphthalen-1-yl)Ethyl) Adipate (21c)}

Yield 50\% from adipic acid (a colorless solid); IR (neat) 2986, 2928, 1728, 1375, 1227, 1188, 1057, 822, $748 \mathrm{~cm}^{-1}$; ${ }^{1} \mathrm{H}$ NMR (300 MHz, $\left.\mathrm{CDCl}_{3}\right) \delta=1.59(\mathrm{~d}, J=6.5 \mathrm{~Hz}, 6 \mathrm{H}), 1.62$ $1.72(\mathrm{~m}, 4 \mathrm{H}), 2.30-2.42(\mathrm{~m}, 4 \mathrm{H}), 6.03(\mathrm{q}, J=6.5 \mathrm{~Hz}, 2 \mathrm{H}), 7.41-7.51(\mathrm{~m}, 6 \mathrm{H}), 7.75-$ $7.87(\mathrm{~m}, 8 \mathrm{H}) ;{ }^{13} \mathrm{C}$ NMR $\left(125 \mathrm{MHz}, \mathrm{CDCl}_{3}\right) \delta=21.8,24.5,34.3,69.5,123.3,125.4,125.8$, $126.4,128.5,129.0,130.3,133.9,137.5,172.7 ; \mathrm{MS} \mathrm{m} / \mathrm{z}$ (EI, rel intensities) $454\left(\mathrm{M}^{+}\right.$, 40\%), 299 (2.7), 171 (100), 155 (100), 129 (48); HRMS m/z (EI) 454.2146 (calcd for $\mathrm{C}_{30} \mathrm{H}_{30} \mathrm{O}_{4}: 454.2144, \mathrm{M}^{+}$).

\subsubsection{Mix-Bis(4-Phenylbutan-2-yl) Adipate (22c)}

Yield 69\% from adipic acid (a colorless oil); IR (neat) 2974, 2934, 2864, 2363, 0730, $1495,1454,1377,1244,1177,1130,1051,748,700 \mathrm{~cm}^{-1} ;{ }^{1} \mathrm{H}$ NMR (500 MHz, $\left.\mathrm{CDCl}_{3}\right) \delta$ $=1.24(\mathrm{~d}, J=6.5 \mathrm{~Hz}, 6 \mathrm{H}), 1.62-1.73(\mathrm{~m}, 4 \mathrm{H}), 1.75-1.84(\mathrm{~m}, 2 \mathrm{H}), 1.87-1.97(\mathrm{~m}, 2 \mathrm{H})$, $2.26-2.36(\mathrm{~m}, 4 \mathrm{H}), 2.55-2.70(\mathrm{~m}, 4 \mathrm{H}), 4.94\left(\mathrm{tq}, J_{1}=J_{2}=6.0 \mathrm{~Hz}, 2 \mathrm{H}\right), 7.14-7.21(\mathrm{~m}$, $6 \mathrm{H}), 7.24-7.31(\mathrm{~m}, 4 \mathrm{H}) ;{ }^{13} \mathrm{C} \mathrm{NMR}\left(125 \mathrm{MHz}, \mathrm{CDCl}_{3}\right) \delta=20.1,24.5,31.8,34.3,70.4$, 125.9, 128.3, 128.4, 141.5, 173.0; MS m/z (EI, rel intensities) $410\left(\mathrm{M}^{+}, 11.6 \%\right), 273$ (9.2), 235 (21), 177 (8.4), 164 (6.5), 149 (12), 133 (100), 106 (100); HRMS m/z (EI) 410.2457 (calcd for $\mathrm{C}_{26} \mathrm{H}_{34} \mathrm{O}_{4}: 410.2457, \mathrm{M}^{+}$).

\subsubsection{Mix-Bis(4-(Benzyloxy)Butan-2-yl) Adipate (23c)}

Yield 51\% from adipic acid (a colorless oil); IR (neat) 2976, 2934, 2864, 1730, 1497, 1453, 1377, 1246, 1180, 1099, 912, 745, $698 \mathrm{~cm}^{-1} ;{ }^{1} \mathrm{H}$ NMR $\left(500 \mathrm{MHz}, \mathrm{CDCl}_{3}\right) \delta=1.23$ $(\mathrm{d}, J=6.5 \mathrm{~Hz}, 6 \mathrm{H}), 1.55-1.65(\mathrm{~m}, 4 \mathrm{H}), 1.76-1.93(\mathrm{~m}, 4 \mathrm{H}), 2.19-2.28(\mathrm{~m}, 4 \mathrm{H}), 3.44$ $3.53(\mathrm{~m}, 4 \mathrm{H}), 4.468(\mathrm{~d}, J=12.0 \mathrm{~Hz}, 2 \mathrm{H}), 4.472(\mathrm{~d}, J=12.0 \mathrm{~Hz}, 2 \mathrm{H}), 5.03-5.12(\mathrm{~m}, 2 \mathrm{H})$, $7.24-7.38(\mathrm{~m}, 10 \mathrm{H}) ;{ }^{13} \mathrm{C} \mathrm{NMR}\left(125 \mathrm{MHz}, \mathrm{CDCl}_{3}\right) \delta=20.4,24.5,34.3,36.1,66.7,68.5$, 68.8, 73.1, 127.7, 127.8, 128.5, 138.4, 172.9; MS m/z (EI, rel intensities) $470\left(\mathrm{M}^{+}, 2.8 \%\right)$, 379 (38), 363 (13), 273 (100), 201 (100), 183 (100), 162 (100), 108 (100); HRMS m/z (EI) 470.2705 (calcd for $\mathrm{C}_{28} \mathrm{H}_{38} \mathrm{O}_{6}: 470.2668, \mathrm{M}^{+}$).

\subsection{Enzymatic Hydrolysis of Mix-4c with Novozym 435}

\subsubsection{Typical Procedure}

To a $200-\mathrm{mL}$ Erlenmeyer flask containing $142 \mathrm{mg}$ of $m i x-4 \mathrm{c}(0.401 \mathrm{mmol})$ was added $40 \mathrm{~mL}$ of $0.1 \mathrm{M}$ phosphate buffer ( $\mathrm{pH} 6.5$ ). To the mixture was added $40 \mathrm{mg}$ of No- 
vozym 435 (Sigma L4777, >5.0 U/mg), and the flask was shaken at $120 \mathrm{~min}^{-1}$ for $24 \mathrm{~h}$ at $30^{\circ} \mathrm{C}$. After addition of $2 \mathrm{M} \mathrm{HCl}$ to the mixture, the products were extracted with $\mathrm{Et}_{2} \mathrm{O}$ $(\mathrm{x} 3)$, and the organic layer was washed with brine and dried over $\mathrm{Na}_{2} \mathrm{SO}_{4}$. After the organic phase was evaporated in vacuo, the residue was purified by flash column chromatography on silica gel (hexane/AcOEt $=7 / 1-3 / 1)$ to give $(S, S)-4 \mathrm{c}(34.1 \mathrm{mg}, 25 \%,>99 \%$ ee), (S)-3c (47.4 mg, 50\%, >99\% ee), and $(R)-2$ (47.0 mg, 96\%, >99\% ee). The ee of $(R)-2$ was determined by GC analysis with a chiral column. The remaining $(S, S)-4 \mathrm{c}$ and $(S)-3 c$ were chemically hydrolyzed with $2 \mathrm{M} \mathrm{NaOH}$ in $\mathrm{MeOH}$ and in $\mathrm{H}_{2} \mathrm{O}$, respectively, to afford the corresponding alcohol $(S)-2$. The ee of the resulting $(S)-2$ was regarded as the ee of the original ester.

GC conditions: column, CP-Cyclodextrin-B-236-M19 (Agilent Technologies, Inc.), $0.25 \mathrm{~mm} \times 50 \mathrm{~m}$; injection, $140^{\circ} \mathrm{C}$; detection, $140^{\circ} \mathrm{C}$; oven, $120^{\circ} \mathrm{C}$; carrier gas, $\mathrm{He}$; head pressure, $2.4 \mathrm{~kg} / \mathrm{cm}^{2}$; retention time, $14.6(R)$ and $15.2(S) \mathrm{min}$.

\subsubsection{Preparative Scale Procedure}

To 3000-mL Erlenmeyer flask containing $1.43 \mathrm{~g}$ of $\mathrm{mix}-4 \mathrm{c}(4.00 \mathrm{mmol})$ was added 400 $\mathrm{mL}$ of $0.1 \mathrm{M}$ phosphate buffer ( $\mathrm{pH}$ 6.5). To the mixture was added $400 \mathrm{mg}$ of Novozym 435 , and the flask was shaken at $120 \mathrm{~min}^{-1}$ for $24 \mathrm{~h}$ at $30^{\circ} \mathrm{C}$. After addition of $2 \mathrm{M} \mathrm{HCl}$ to the mixture, the products were extracted with $\mathrm{Et}_{2} \mathrm{O}(\mathrm{x} 3)$, and the organic layer was washed with brine and dried over $\mathrm{Na}_{2} \mathrm{SO}_{4}$. After the organic phase was evaporated in vacuo, the residue was purified by flash column chromatography on silica gel (hexane/ $\left.\mathrm{Et}_{2} \mathrm{O}=6 / 1\right)$ to give $(S, S)-4 \mathrm{c}(330 \mathrm{mg}, 23 \%),(S)-3 \mathrm{c}(492 \mathrm{mg}, 49 \%)$, and $(R)-2(484$ $\mathrm{mg}, 99 \%,>99 \%$ ee). All the spectral data $\left({ }^{1} \mathrm{H}\right.$ and ${ }^{13} \mathrm{C} \mathrm{NMR}, \mathrm{IR}$, and MS) of $4 \mathrm{c}$ and 2 were in full agreement with those of the racemate $4 \mathrm{c}$ and the commercial source 2 , respectively.

$(S, S)-4 \mathrm{c}:[\alpha]_{\mathrm{D}}{ }^{26}=-86.9(\mathrm{c} 1.29, \mathrm{MeOH})$.

(S)-3c: IR (neat) 2955, 1736, 1709, 1495, 1452, 1375, 1287, 1175, 1065, 762, $700 \mathrm{~cm}^{-1}$; ${ }^{1} \mathrm{H}$ NMR $\left(500 \mathrm{MHz}, \mathrm{CDCl}_{3}\right) \delta=1.53(\mathrm{~d}, J=6.5 \mathrm{~Hz}, 3 \mathrm{H}), 1.60-1.73(\mathrm{~m}, 4 \mathrm{H}), 2.29-2.42$ $(\mathrm{m}, 4 \mathrm{H}), 5.89(\mathrm{q}, J=6.5 \mathrm{~Hz}, 1 \mathrm{H}), 7.25-7.38(\mathrm{~m}, 5 \mathrm{H}) ;{ }^{13} \mathrm{C} \mathrm{NMR}\left(125 \mathrm{MHz}, \mathrm{CDCl}_{3}\right) \delta=$ 22.3, 24.1, 24.4, 33.7, 34.3, 72.4, 126.2, 128.0, 128.6, 141.7, 172.7, 179.6; MS m/z (EI, rel intensities) $250\left(\mathrm{M}^{+}, 66 \%\right), 222$ (91), 129 (100), 121 (100); HRMS m/z (EI) 250.1200 (calcd for $\left.\mathrm{C}_{14} \mathrm{H}_{18} \mathrm{O}_{4}: 250.1205, \mathrm{M}^{+}\right) ;[\alpha]_{\mathrm{D}}{ }^{25}=-61.6(\mathrm{c} 1.08, \mathrm{MeOH})$.

$(R)-2:[\alpha]_{\mathrm{D}}{ }^{24}=+38.4(\mathrm{c} 1.04, \mathrm{MeOH})\left(>99 \%\right.$ ee); lit. $[\alpha]_{\mathrm{D}}{ }^{20}=+45$ (c 5.15, MeOH) [8].

To the diester $(S, S)-4 \mathrm{c}$ in $\mathrm{MeOH}(5 \mathrm{~mL})$ was added $2 \mathrm{M} \mathrm{NaOH}(2 \mathrm{~mL})$, and the mixture was stirred at rt. The products were extracted with $\mathrm{Et}_{2} \mathrm{O}(\mathrm{x} 3)$, and the organic layer was washed with brine and dried over $\mathrm{Na}_{2} \mathrm{SO}_{4}$. After the organic phase was evaporated in vacuo, the residue was purified by flash column chromatography on silica gel (hexane/AcOEt $=2 / 1)$ to give $(S)-2(213 \mathrm{mg}, 188 \%,>99 \%$ ee).

To the monoester $(S)-3 \mathrm{c}$ was added $2 \mathrm{M} \mathrm{NaOH}(5 \mathrm{~mL})$, and the mixture was stirred at rt. The products were extracted with $\mathrm{Et}_{2} \mathrm{O}(\mathrm{x} 3)$, and the organic layer was washed with brine and dried over $\mathrm{Na}_{2} \mathrm{SO}_{4}$. After the organic phase was evaporated in vacuo, the residue was purified by flash column chromatography on silica gel (hexane/AcOEt $=$ $2 / 1$ ) to give $(S)-2(215 \mathrm{mg}, 90 \%,>99 \%$ ee $)$.

$(S)-2:[\alpha]_{\mathrm{D}}^{28}=-43.0($ c $1.13, \mathrm{MeOH})(>99 \%$ ee $)$. 


\subsection{Data for the Alcohols Derived from the Enzymatic Hydrolysis of Mix-Dicarboxylic Acid Diesters}

The reactions of the other substrates were carried out by the same procedure. The results were shown in the text. All the spectral data $\left({ }^{1} \mathrm{H}\right.$ and ${ }^{13} \mathrm{C} \mathrm{NMR}, \mathrm{IR}$, and MS) were in full agreement with those of the racemates, commercial sources, or those reported.

1-phenylpropan-1-ol (6)

(S)-6: $[\alpha]_{\mathrm{D}}{ }^{23}=-44.5$ (c 1.26, $\left.\mathrm{CHCl}_{3}\right)(>99 \% \text { ee); lit. [ } \alpha]_{\mathrm{D}}{ }^{20}=-47.0$ (c 1.00, $\mathrm{CHCl}_{3}$ ) [9].

$(R)-6:[\alpha]_{\mathrm{D}}^{24}=+44.2\left(\mathrm{c} 1.83, \mathrm{CHCl}_{3}\right)(>99 \%$ ee $)$.

GC conditions: column, CP-Cyclodextrin-B-236-M19 (Chrompack), $0.25 \mathrm{~mm} \times 50$ $\mathrm{m}$; injection, $140^{\circ} \mathrm{C}$; detection, $140^{\circ} \mathrm{C}$; oven, $120^{\circ} \mathrm{C}$; carrier gas, He; head pressure, 2.4 $\mathrm{kg} / \mathrm{cm}^{2}$; retention time, $22.6(R)$ and $23.4(S) \mathrm{min}$.

1-phenylpropan-2-ol (7)

$(S)-7:[\alpha]_{\mathrm{D}}{ }^{26}=-32.6\left(\mathrm{c} 1.67, \mathrm{CHCl}_{3}\right)(>99 \%$ ee $)$.

$(R)-7:[\alpha]_{\mathrm{D}}{ }^{26}=+40.3\left(\right.$ c $\left.0.49, \mathrm{CHCl}_{3}\right)\left(>99 \%\right.$ ee); lit. $[\alpha]_{\mathrm{D}}{ }^{20}=-37.6$ (c 5.00, $\left.\mathrm{CHCl}_{3}\right)$ [10].

GC conditions: column, CP-Cyclodextrin-B-236-M19 (Chrompack), $0.25 \mathrm{~mm} \times 50$ $\mathrm{m}$; injection, $130^{\circ} \mathrm{C}$; detection, $130^{\circ} \mathrm{C}$; oven, $110^{\circ} \mathrm{C}$; carrier gas, He; head pressure, 2.4 $\mathrm{kg} / \mathrm{cm}^{2}$; retention time, $27.1(R)$ and $27.5(S) \mathrm{min}$.

1-(2-naphthyl)ethanol (8)

$(S)-8:[\alpha]_{\mathrm{D}}^{24}=-36.2($ c $0.86, \mathrm{MeOH})(>99 \%$ ee $)$.

$(R)-8:[\alpha]_{\mathrm{D}}^{25}=+37.4(\mathrm{c} 1.10, \mathrm{MeOH})(>99 \%$ ee $)$; lit. $[\alpha]_{\mathrm{D}}=+34.6(\mathrm{c} 1.20, \mathrm{MeOH})[11]$.

GC conditions: column, CP-Cyclodextrin-B-236-M19 (Chrompack), $0.25 \mathrm{~mm} \times 50$ $\mathrm{m}$; injection, $180^{\circ} \mathrm{C}$; detection, $180^{\circ} \mathrm{C}$; oven, $160^{\circ} \mathrm{C}$; carrier gas, He; head pressure, 2.4 $\mathrm{kg} / \mathrm{cm}^{2}$; retention time, $41.9(R)$ and $42.9(S) \mathrm{min}$.

1-(1-naphthyl)ethanol (9)

$(S)-8:[\alpha]_{\mathrm{D}}^{23}=-13.2(\mathrm{c} 0.84, \mathrm{MeOH})(49 \%$ ee $)$.

$(R)-8:[\alpha]_{\mathrm{D}}{ }^{24}=+22.3(\mathrm{c} 0.61, \mathrm{MeOH})\left(75 \%\right.$ ee); lit. $[\alpha]_{\mathrm{D}}{ }^{25}=+45.0$ (c 2.00, $\left.\mathrm{MeOH}\right)$ [12].

GC conditions: column, CP-Cyclodextrin-B-236-M19 (Chrompack), $0.25 \mathrm{~mm} \times 50$ $\mathrm{m}$; injection, $180^{\circ} \mathrm{C}$; detection, $180^{\circ} \mathrm{C}$; oven, $16^{\circ} \mathrm{C}$; carrier gas, He; head pressure, 2.4 $\mathrm{kg} / \mathrm{cm}^{2}$; retention time, $43.0(R)$ and $44.3(S) \mathrm{min}$.

4-phenylbutan-2-ol (10)

(S)-10: $[\alpha]_{\mathrm{D}}^{27}=+11.9\left(\mathrm{c} 1.04, \mathrm{CHCl}_{3}\right)(98 \% \mathrm{ee})$.

$(R)-11:[\alpha]_{\mathrm{D}}{ }^{27}=-13.1\left(\mathrm{c} 0.83, \mathrm{CHCl}_{3}\right)(81 \%$ ee $)$; lit. $[\alpha]_{\mathrm{D}}{ }^{21}=-14.0$ (c $\left.1.63, \mathrm{CHCl}_{3}\right)$ [13].

HPLC conditions: column, CHIRALCEL OD-H (Daicel Chemical Industries, Ltd.); eluent, hexane/2-propanol $=90 / 10$; flow rate, $0.5 \mathrm{~mL} / \mathrm{min} ; 254 \mathrm{~nm}$; temperature, $25^{\circ} \mathrm{C}$; retention time, $12.6(R)$ and $16.3(S) \mathrm{min}$.

4-benzyloxybutan-2-ol (11)

$(S)-11:[\alpha]_{\mathrm{D}}{ }^{24}=+14.5(\mathrm{c} 1.34, \mathrm{MeOH})\left(99 \%\right.$ ee); lit. $[\alpha]_{\mathrm{D}}{ }^{27}=+19.0($ c $0.95, \mathrm{MeOH})$ [14].

$(R)-11:[\alpha]_{\mathrm{D}}^{25}=-12.3(\mathrm{c} 1.05, \mathrm{MeOH})(91 \% \mathrm{ee})$.

HPLC conditions: column, CHIRALCEL OD-H (Daicel Chemical Industries, Ltd.); eluent, hexane $/ 2$-propanol = 90/10; flow rate, $0.5 \mathrm{~mL} / \mathrm{min} ; 254 \mathrm{~nm}$; temperature, $25^{\circ} \mathrm{C}$; 
retention time, $12.8(S)$ and $14.0(R)$ min.

\subsection{Enzymatic Hydrolysis of $( \pm)$-Acetates Derived from Alcohols with Novozym 435}

Racemic acetates were prepared from the corresponding alcohols by a usual method using acetic anhydride in pyridine.

Enzymatic reactions of the acetates were carried out using $20 \mathrm{mM}$ of the substrates with Novozyme $435(40 \mathrm{mg})$ in $0.1 \mathrm{M}$ phosphate buffer $(\mathrm{pH} 6.5,40 \mathrm{~mL})$ at $30^{\circ} \mathrm{C}$ for 24 $\mathrm{h}$. The analytical methods of the products were almost same as those in the case of the dicarboxylic acid diesters mentioned above.

\section{Results and Discussion}

\subsection{Concept of the Enzymatic Hydrolysis of Dicarboxylic Acid Diesters}

Based on our concept of the enzymatic hydrolysis of $m i x-4$, the process involving the production of $(R)-2$ contains two different steps, which are the first hydrolysis of the diesters mix-4 and the following second hydrolysis of the resulting monoester 3 (Scheme 3). When the reactions of the diesters mix-4, which contains the racemates $((S, S)-4$ and $(R, R)-4)$ and meso-4 in the ratio 1:1, theoretically proceed, the yield of the resulting alcohol $(R)-2$ could be $100 \%$. In a similar way, the unreactive $(S, S)-4$ and (S)-3 could be obtained in $25 \%$ and $50 \%$ yields, respectively, and the following chemical hydrolysis of esters 4 and 3 could also give (S)-2 in 100\% total yield based on the amount of mix-4. According to our previous study [6], the highly enantioselective hydrolysis of monoesters ( \pm )-3 using Novozym 435 should be expected. We then specifically focused on the reactivity of the diesters 4 .

\subsection{Preparation of Racemic Dicarboxylic Acid Diesters as the Substrate}

For the synthesis of the substrates, the racemate ( \pm )-2 was combined with succinic anhydride or glutaric anhydride using DMAP in $\mathrm{CH}_{2} \mathrm{Cl}_{2}$ to give the corresponding ( \pm )-3a $(n=2)$ and $3 \mathrm{~b}(n=3)$, respectively (Scheme 4$)$. The monoesters were coupled with another $( \pm)-2$ using DCC and DMAP in $\mathrm{CH}_{2} \mathrm{Cl}_{2}$ to afford the substrates mix-4a and $\mathbf{4 b}$, respectively. On the other hand, the diesters mix-4c $(n=4), 4 \mathrm{~d}(n=5), 4 \mathrm{e}(n=6)$ and $4 \mathbf{f}(n=8)$ were prepared by the direct coupling of $( \pm)-2$ with adipic acid, pimelic acid, suberic acid, and sebacic acid, respectively. The other substrates were synthesized by the same procedure (Scheme 5). HPLC analyses of mix-4b and $\mathbf{4 c}$ showed that the compounds were almost 1:1 mixtures of the diastereomers, and we then decided that the diastereomeric ratios of the prepared diesters 4 should be 1:1, regardless of the synthetic process.

\subsection{Enzymatic Hydrolysis of Racemic Dicarboxylic Diester mix-4}

We initially took notice of the carbon number between the two ester parts of the substrates, and the enzymatic reactions using Novozym 435 of several diesters mix-4a-f were carried out. After the enzymatic reactions of mix-4 $(0.4 \mathrm{mmol})$ using Novozym $435(80 \mathrm{mg})$ in $0.1 \mathrm{M}$ phosphate buffer $(\mathrm{pH} 6.5,40 \mathrm{~mL})$, the isolated yields of the compounds were determined after purification. The remaining diesters and monoesters were 


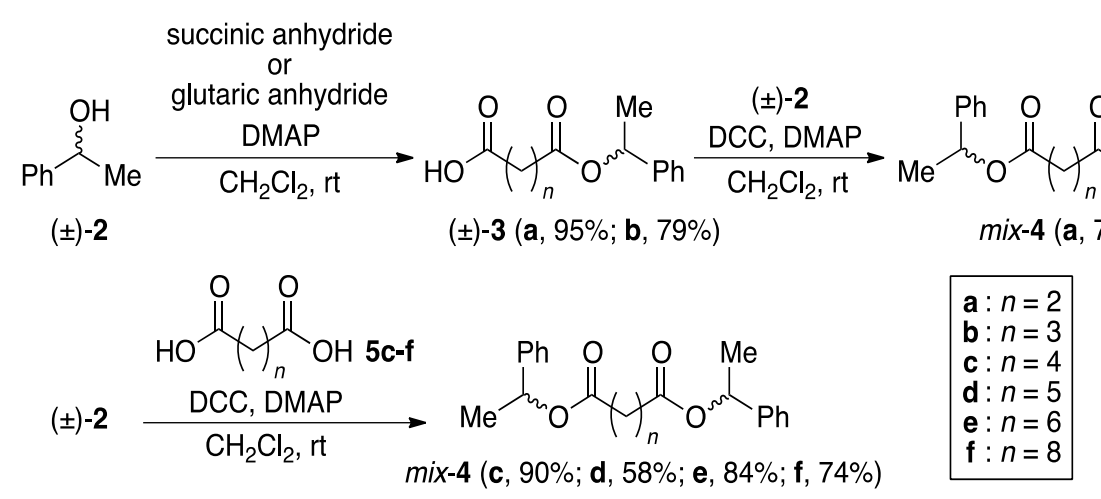

Scheme 4. Synthesis of the substrates mix-4.

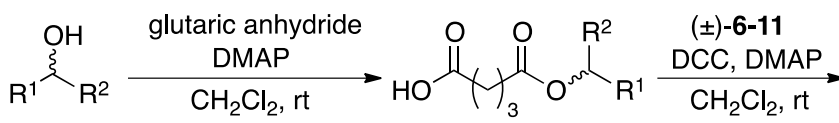

$( \pm)-6-11$

$( \pm)-6-11$

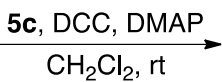

$( \pm)-12 b$

13b

$14 \mathrm{~b}(71 \%)$

$15 b$

$16 \mathrm{~b}(39 \%)$

$17 \mathrm{~b}(60 \%)$

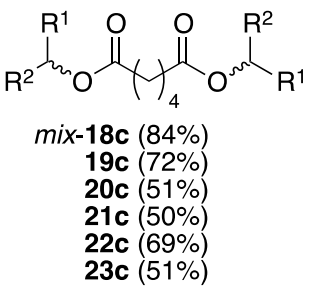

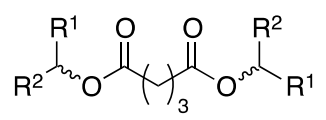

mix-18b (90\% from 6$)$ $19 b$ ( $89 \%$ from 7 ) $20 \mathrm{~b}(74 \%)$ 21b (91\% from 9) 22b $(69 \%)$ 23b $(66 \%)$

6, 12, 18: $R^{1}=P h, R^{2}=E t$ 7, 13, 19: $\mathrm{R}^{1}=\mathrm{PhCH}_{2}, \mathrm{R}^{2}=\mathrm{Me}$ 8, 14, 20: $R^{1}=2$-naphtyl, $R^{2}=M e$ 9, 15, 21: $R^{1}=1$-naphtyl, $R^{2}=M e$ 10, 16, 22: $\mathrm{R}^{1}=\mathrm{Ph}\left(\mathrm{CH}_{2}\right)_{2}, \mathrm{R}^{2}=\mathrm{Me}$ 11, 17, 23: $\mathrm{R}^{1}=\mathrm{BnO}\left(\mathrm{CH}_{2}\right)_{2}, \mathrm{R}^{2}=\mathrm{Me}$

b: $n=3$ c: $n=4$

Scheme 5. Synthesis of the substrates mix-18b-23b and $\mathbf{1 8 c - 2 3 c .}$

sequentially hydrolyzed with $\mathrm{NaOH}$. The enantiomeric excesses (ee) of the resulting 2 were evaluated by a chiral GLC analysis, and the results are summarized in Table 1. Surprisingly, in all cases, the enzymatic hydrolyses of 4 proceeded with excellent enantioselectivities to afford the corresponding optically active compounds. Furthermore, the excellent ee values of the resulting $(R)-2$ from the enzymatic reactions showed that the enantioselectivities of the hydrolysis of not only the monoesters 3 but also the diesters 4 are almost perfect under the stated reaction conditions. Interestingly, the ee of (S)-2 derived from $\mathbf{4 a}$ (Entry 1), which has the lowest number $n$, was relatively low $(83 \%)$, and almost the same result was obtained in the case of $4 \mathrm{f}(80 \%)$, which has the highest number $n$ (Entry 6). In these cases, longer reaction times $(48 \mathrm{~h})$ did not improve the conversions and the ees of 4 , although the reason was not clear yet. These results indicated that the enzyme prefers the substrates bearing a moderate carbon number between two carboxylates in the first enzymatic hydrolysis, and the higher reaction rates of $\mathbf{4 b}(n=3$, Entry 2$)$ and $4 \mathbf{c}(n=4$, Entry 3$)$ caused the higher ees of $(S)-2$ derived from $4 \mathrm{~b}$ and $\mathbf{4 c}$. Finally, we determined that glutarate and adipate were the most suitable substrates ( $\mathbf{4 b}$ and $\mathbf{4 c}$, respectively) for this enzymatic reaction.

We next studied the time-course of the reaction for $\mathbf{4 c}$ using a smaller amount of enzyme ( $40 \mathrm{mg}$ for $0.4 \mathrm{mmol}$ of substrate), and the results are shown in Table 2 . 
Table 1. Enantioselective hydrolysis of dicarboxylic diesters mix-4a-f with Novozym $435^{\text {a }}$.

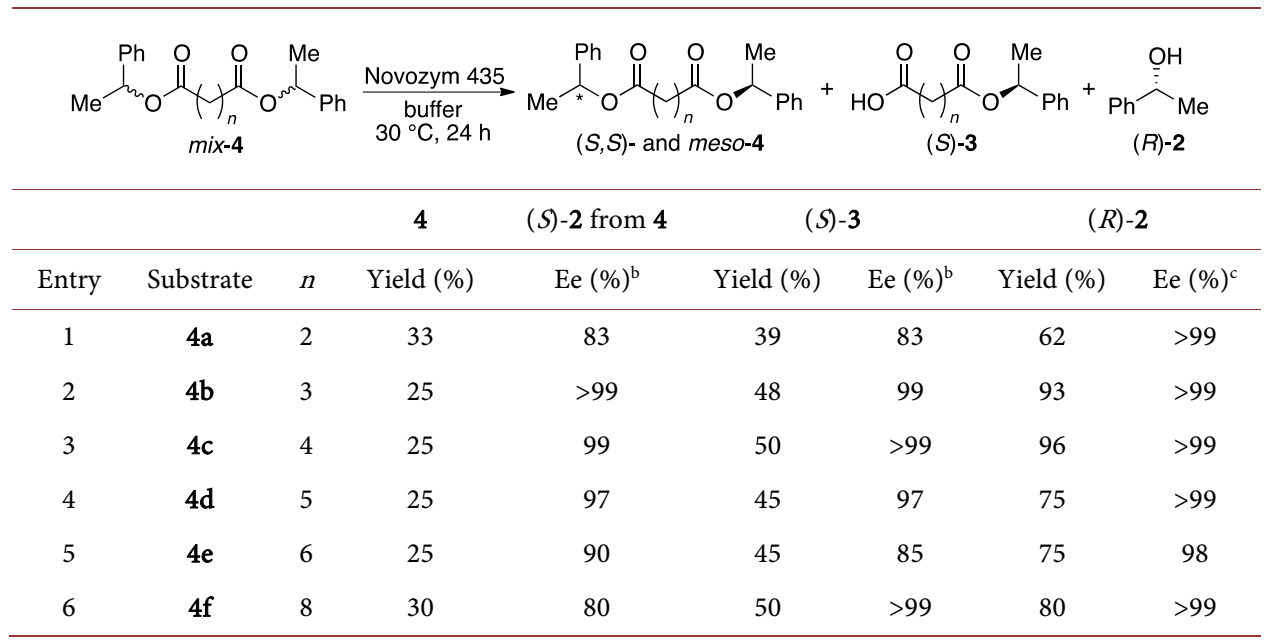

${ }^{\mathrm{a}}$ The reaction was performed using the substrate $(4.00 \mathrm{mmol})$ with Novozym $435(80 \mathrm{mg})$ in $0.1 \mathrm{M}$ phosphate buffer $\left(\mathrm{pH} 6.5,40 \mathrm{~mL}\right.$ ) for $24 \mathrm{~h}$ at $30^{\circ} \mathrm{C}$. ${ }^{b}$ Determined by GC analysis of $(S)-2$ after chemical hydrolysis. ${ }^{\mathrm{c}}$ Determined by GC analysis.

Table 2. Enzymatic enantioselective hydrolysis of dicarboxylic diester $m i x-4 c^{a}$.

\begin{tabular}{|c|c|c|c|c|c|c|c|}
\hline & $\begin{array}{l}m_{4} \\
m i x-4 c\end{array}$ & h $\begin{array}{r}\text { Novozy } \\
\begin{array}{r}\text { buf } \\
30\end{array}\end{array}$ & $\mathrm{Me}_{(S, S)-\mathrm{a}}^{\mathrm{Ph}}$ & $\overbrace{\text { meso-4c }}^{\mathrm{O}} \overbrace{\mathrm{Ph}}^{\mathrm{Me}}$ & ${ }_{10}^{\mathrm{O}}$ & ${ }_{0}^{\mathrm{Me}}{ }_{\mathrm{O}}^{\mathrm{C}}$ & $\overbrace{(R)-2}^{\stackrel{O}{\overbrace{i}}}$ \\
\hline \multirow[b]{2}{*}{ Entry } & \multirow[b]{2}{*}{ Time (h) } & $4 c$ & \multirow{2}{*}{$\frac{(S)-2 \text { from } 4 c}{\text { Ee }(\%)^{\mathrm{b}}}$} & \multicolumn{2}{|c|}{$(S)-3 c$} & \multicolumn{2}{|c|}{$(R)-2$} \\
\hline & & Yield (\%) & & Yield (\%) & $\mathrm{Ee}(\%)^{\mathrm{b}}$ & Yield (\%) & $\mathrm{Ee}(\%)^{\mathrm{c}}$ \\
\hline 1 & 1 & 43 & 33 & 31 & 65 & 59 & $>99$ \\
\hline 2 & 12 & 24 & 97 & 45 & $>99$ & 90 & $>99$ \\
\hline 3 & 24 & 25 & $>99$ & 50 & $>99$ & 96 & $>99$ \\
\hline
\end{tabular}

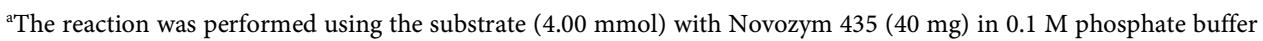
$\left(\mathrm{pH} 6.5,40 \mathrm{~mL}\right.$ ) at $30^{\circ} \mathrm{C}$. ${ }^{b}$ Determined by GC analysis of $(S)-2$ after chemical hydrolysis. ${ }^{\circ}$ Determined by GC analysis.

Beyond our expectation, the reaction for only $1 \mathrm{~h}$ smoothly proceeded to afford the optically pure $(R)-2$ in $59 \%$ yield (Entry 1 ). In the case of the reaction for $12 \mathrm{~h}$, the yield of $(R)$ - 2 reached $90 \%$, and the ee of $(S)-2$ from the monoester $3 c$ was $>99 \%$ (Entry 2 ). According to the slightly lower ee (97\%) of $(S)$-2 from the diester $4 c$, it was proposed that the enantioselective hydrolysis of $\mathbf{4 c}$ should be slower than that of $\mathbf{3 c}$. Finally, the reaction for $24 \mathrm{~h}$ gave the complete resolution (Entry 3 ). The yields of the products $(R)-2,(S)-3 c$, and $(S, S)-4 c$ were $96 \%, 50 \%$, and $25 \%$, respectively, and the ees of all the compounds 2 were over $99 \%$. This reaction was also useful in a preparative-scale operation $(1.43 \mathrm{~g}$ of $3 \mathrm{c})$ using an Erlenmeyer flask for $24 \mathrm{~h}$ at $30^{\circ} \mathrm{C}$. We obtained $(R)-2$ $(>99 \%$ ee) in $100 \%$ and $(S)-2$ ( $>99 \%$ ee) in $88 \%$ total isolated yields from $( \pm)-4 \mathrm{c}$.

\subsection{Enzymatic Hydrolysis of Various Dicarboxylic Diesters}

In order to apply the concept of this reaction to the kinetic resolution of other secondary alcohols, we next examined the enzymatic hydrolysis of several glutarates and adipates (18-23; $n=3$ and 4 , respectively), and these results are shown in Table 3. In the cases 
Table 3. Enzymatic enantioselective hydrolysis of dicarboxylic diesters mix-18-23 .

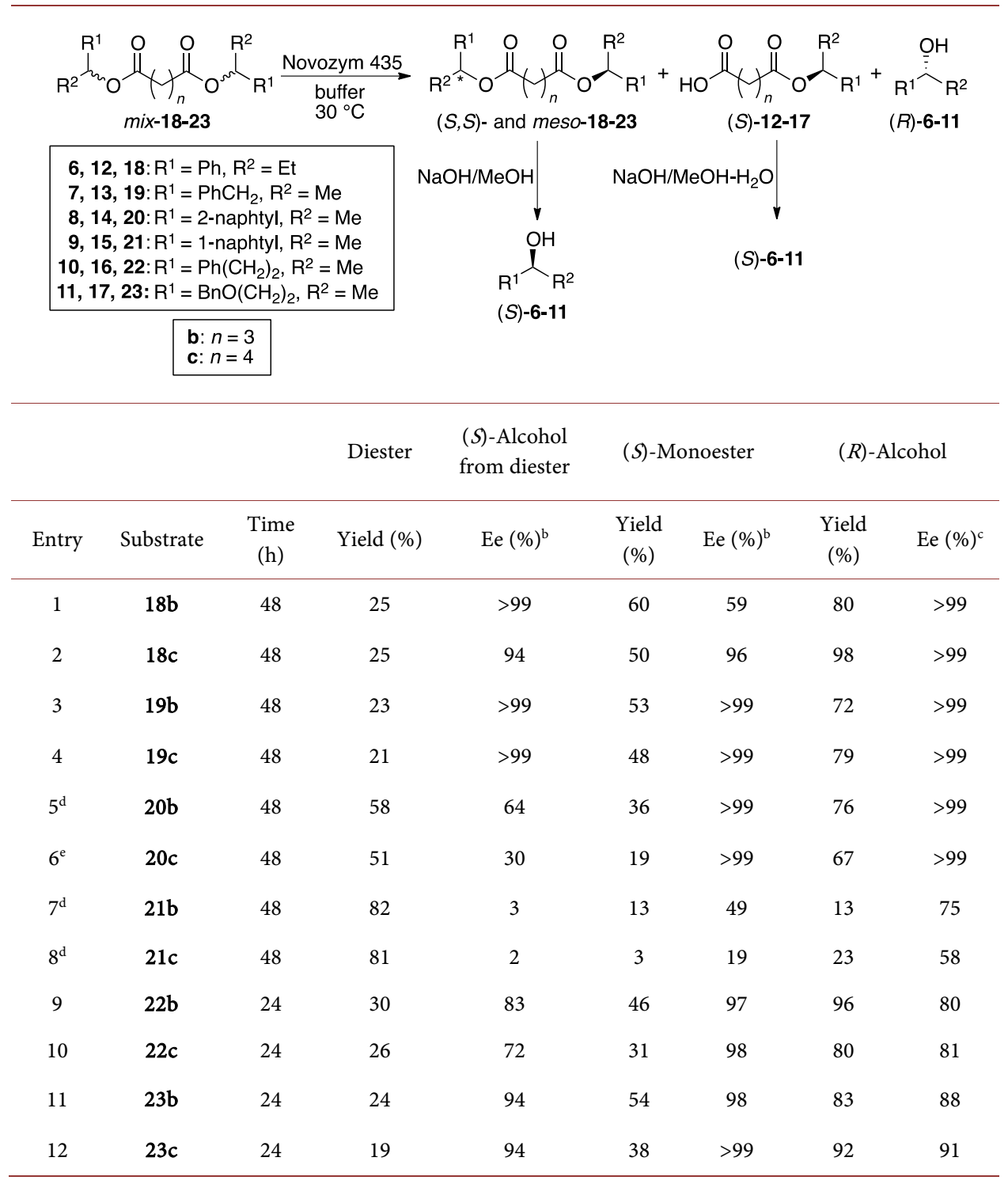

${ }^{\mathrm{a}}$ Unless otherwise noted, the reaction was performed using the substrate $(4.00 \mathrm{mmol})$ with Novozym $435(40 \mathrm{mg})$ in $0.1 \mathrm{M}$ phosphate buffer $(\mathrm{pH} 6.5,40 \mathrm{~mL})$ at $30^{\circ} \mathrm{C}$. ${ }^{b}$ Determined by GC or HPLC analysis of the corresponding (S)-alcoholafter chemical hydrolysis. ${ }^{c}$ Determined by GC or HPLC analysis. ${ }^{\mathrm{d}}$ The reaction was performed in the mixed solvent of $0.1 \mathrm{M}$ phosphate buffer $\left(\mathrm{pH}\right.$ 6.5) containing $10 \% \mathrm{Pr}_{2} \mathrm{O}$. ${ }^{e}$ The reaction was performed in the mixed solvent of $0.1 \mathrm{M}$ phosphate buffer ( $\mathrm{pH} 6.5$ ) containing $25 \%{ }_{2} \mathrm{Pr}_{2} \mathrm{O}$.

of entries 1-8, the reactions were performed for a longer reaction time $(48 \mathrm{~h})$ because the reactivities were lower than that in the case of the substrate 4 .

The hydrolyses of both the glutarate mix-18b and the adipate mix-18c bearing an ethyl group as the $\mathrm{R}^{2}$ substituent $\left(\mathrm{R}^{1}=\mathrm{Ph}, \mathrm{R}^{2}=\mathrm{Et}\right)$ smoothly proceeded with excellent enantioselectivities to afford the optically pure alcohol $(R)-6$. However, in the case of Entry 1 , the hydrolysis of the monoester $12 \mathrm{~b}$ was slower than that of the diester $18 \mathrm{~b}$, and then the ee of monoester $(S)-12 b$ was low. This tendency was quite different from that in the case of 4 previously mentioned. In the cases of mix-19b and $19 \mathrm{c}$ bearing a phenylmethyl group $\left(\mathrm{R}^{1}=\mathrm{PhCH}_{2}, \mathrm{R}^{2}=\mathrm{Me}\right)$, the enzyme completely discriminated the enantiomers to afford the optically pure products in a manner similar to 4 (entries 3 and 4). 
Although the diesters $m i x-20 \mathrm{~b}$ and $20 \mathrm{c}$ bearing a 2-naphthyl group $\left(\mathrm{R}^{1}=2\right.$-naphthyl, $\mathrm{R}^{2}=\mathrm{Me}$ ) were slowly hydrolyzed (entries 5 and 6 ), the enantioselectivities were excellent and the optically pure $(S)-14$ and $(R)-8$ were obtained. On the other hand, both the reactivities and enantioselectivities of the diesters ( $m i x-21 \mathrm{~b}$ and $21 \mathrm{c} ; \mathrm{R}^{1}=1$-naphthyl, $\mathrm{R}^{2}=\mathrm{Me}$ ) of 1-(1-naphthyl)ethanol (9) were extremely low (entries 7 and 8). These results indicated that the 1-naphthyl group would be too bulky for the interaction between the substrate and the enzyme. Interestingly, the enzymatic reactions of the diesters mix-22 b, $22 \mathrm{c}$ and mix-23b, 23c, which contain a phenylethyl $\left(\mathrm{R}^{1}=\mathrm{PhCH}_{2} \mathrm{CH}_{2}, \mathrm{R}^{2}\right.$ $=\mathrm{Me}$; entries 9 and 10) and benzyloxyethyl group $\left(\mathrm{R}^{1}=\mathrm{BnOCH}_{2} \mathrm{CH}_{2}, \mathrm{R}^{2}=\mathrm{Me}\right.$; entries 11 and 12), respectively, smoothly proceeded for only $24 \mathrm{~h}$ with sufficient enantioselectivities to give the corresponding optically active compounds. It is noteworthy that the ees of the monoesters $(S)-17 b$ and $17 \mathrm{c}$ were higher than those of the alcohol $(S)-11$ derived the remaining diesters $23 \mathrm{~b}$ and $23 \mathrm{c}$, and the resulting alcohols $(R)-11$ were not of the optically pure form. In our previous report, the kinetic resolution of the monoester ( \pm )-17b with Novozym 435 was completely accomplished to afford the almost optically pure alcohol $11(E$ value $=920)$ under the same reaction conditions. These results indicated that the enantioselectivities of the first enzymatic hydrolyses of $m i x-23 b$ and $23 c$ should be lower than those of the second reactions of $( \pm)-17 b$ and $17 c$.

For comparison, we also examined the enzymatic hydrolysis of the usual acetates derived from the corresponding alcohols 2 and 6 - 11 under the same reaction conditions as mentioned above. Among the reactions of all the acetates, the reactivitiesand/orenantioselectivities in the cases of the acetates $( \pm)-24$ and 25 bearing a 1-naphthyl group and a benzyloxyethyl group, respectively, were quite different from those of the dicarboxylic acid diseters 21 and 23 containing the same substituents, while other acetates were enantioselectively hydrolyzed in a manner similar to the corresponding dicarboxylic acid diseters. Surprisingly, in the case of $24\left(\mathrm{R}^{1}=1\right.$-naphthyl, $\left.\mathrm{R}^{2}=\mathrm{Me}\right)$, the reaction was smoothly accomplished to afford optically active compounds (conv. $=0.49, E$ value = 340; Scheme 6(a)) [15]. On the other hand, the enantioselectivity in the case of $25\left(\mathrm{R}^{1}=\mathrm{BnOCH}_{2} \mathrm{CH}_{2}, \mathrm{R}^{2}=\mathrm{Me}\right)$ was low, although the hydrolysis smoothly proceeded (conv. $=0.44, E$ value $=15$; Scheme $6(\mathrm{~b})$ ). These results indicated that the structure of<smiles>C[C](OC(C)=O)c1cccc2ccccc12</smiles>

$( \pm)-24$

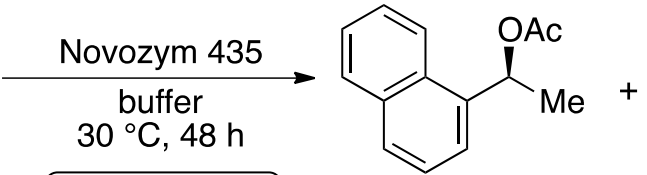

(S) -24

$48 \%, 93 \%$ ee<smiles>C[C@H](O)c1cccc2ccccc12</smiles>

$(R)-9$

$49 \%, 98 \%$ ee

(a)

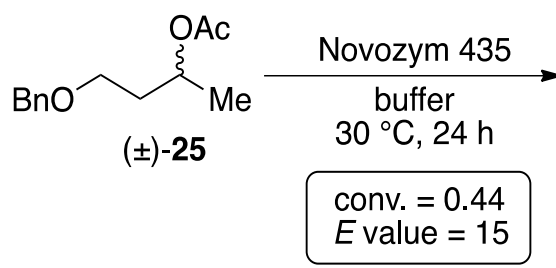<smiles>CC(=O)O[C@@H](C)CCOCc1ccccc1</smiles>

(S) -25

$54 \%, 61 \%$ ee

(b)

Scheme 6. Enzymatic hydrolysis of the acetates ( \pm )-24 and 25 with Novozym 435. 
the acyl moieties apparently affects the interaction between the substrates and the active site of the enzyme, and the use of the dicarboxylic acid diseters as the substrates could bring the latent specificity of molecular recognition in enzymatic hydrolysis.

\section{Conclusion}

In this study, we succeeded in the enzyme-mediated enantioselective hydrolysis of aliphatic dicarboxylic acid diesters, and obtained several enantiomers of 2, 6, 7, 8, 9, 10 and 11 . We also disclosed that the reactivity and enantioselectivity could be controlled using a suitable acyl group of the substrates, and the glutarate and adipate were suitable as the acyl moiety of the substrates. Furthermore, we found that the substrate specificity of the enzyme differed from those in the case of the corresponding acetates. We anticipate that the use of glutarate and adipate for the enzymatic hydrolysis could be an alternative choice as the simple acetates.

\section{Acknowledgements}

We thank Collaborative Research Center (Meisei University) for the analyses of organic compounds, and Mr. Masamune Minegishi (Meisei University) for helpful discussions.

\section{References}

[1] Gotor, V., Alfonso, I. and Garcia-Urdiales, E. (2008) Asymmetric Organic Synthesis with Enzymes. Wiley-VCH, Weinheim. https://doi.org/10.1002/9783527622481

[2] Whittall, J. and Sutton, P.W. (2010) Practical Methods for Biocatalysis and Biotransformations. Wiley, West Sussex.

[3] Tao, J.A. and Kazlauskas, R.J. (2011) Biocatalysis for Green Chemistry and Chemical Process Development. John Wiley \& Sons Inc., New Jersey. https://doi.org/10.1002/9781118028308

[4] Drauz, K., Gröger, H. and May, O. (2012) Enzyme Catalysis in Organic Synthesis. 3rd Edition, Wiley-VCH, Weinheim. https://doi.org/10.1002/9783527639861

[5] Okudomi, M., Shimojo, M., Nogawa, M., Hamanaka, A., Taketa, N., Nakagawa, T. and Matsumoto, K. (2010) Easy Separation of Optically Active Secondary Alcohols by Enzymatic Hydrolysis of Soluble Polymer-Supported Carbonates. Bulletin of the Chemical Society of Japan, 83, 182-189. https://doi.org/10.1246/bcsj.20090271

[6] Kataoka, N., Okudomi, M., Chihara, N. and Matsumoto, K. (2012) Enzyme-Mediated Enantioselective Hydrolysis of Dicarboxylic Acid Monoesters. Letters in Organic Chemistry, 9, 615-621. https://doi.org/10.2174/157017812803521108

[7] Okudomi, M., Nogawa, M., Chihara, N., Kaneko, M. and Matsumoto, K. (2008) EnzymeMediated Enantioselective Hydrolysis of Soluble Polymer-Supported Dendritic Carbonates. Tetrahedron Letters, 49, 6642-6645. https://doi.org/10.1016/j.tetlet.2008.09.030

[8] Laumen, K. and Schneider, M.P. (1988) A Highly Selective Ester Hydrolase from Pseudomonas sp. for the Enzymatic Preparation of Enantiomerically Pure Secondary Alcohols; Chiral Auxiliaries in Organic Synthesis. Journal of the Chemical Society, Chemical Communications, No. 9, 598-600. https://doi.org/10.1039/c39880000598

[9] Nakamura, K., Fujii, M. and Ida, Y. (2001) Stereoinversion of Arylethanols by Geotrichum candidum. Tetrahedron: Asymmetry, 12, 3147-3153. https://doi.org/10.1016/S0957-4166(01)00554-7

[10] Masuda, S., Nakajima, T. and Suga, S. (1983) Retentive Friedel-Crafts Alkylation of Ben- 
zene with Optically Active 2-Chloro-1-phenylpropane and 1-Chloro-2-phenylpropane. Bulletin of the Chemical Society of Japan, 56, 1089-1094. https://doi.org/10.1246/bcsj.56.1089

[11] Ziffer, H., Kawai, K., Kasai, M., Imuta, M. and Froussios, C. (1983) Microbially Mediated Enantioselective Ester Hydrolyses Utilizing Rhizopus Nigricans. A New Method of Assigning the Absolute Stereochemistry of Acyclic 1-Arylalkanols. The Journal of Organic Chemistry, 48, 3017-3021. https://doi.org/10.1021/jo00166a016

[12] Kanth, J.V.B. and Periasamy, M. (1990) Asymmetric Reduction of Prochiral Aromatic Ketones by Borane-Amine Complexes in the Presence of a Chiral Amine-BF 3 Catalyst. Journal of the Chemical Society, Chemical Communications, No. 17, 1145-1147. https://doi.org/10.1039/C39900001145

[13] Kunisu, T., Oguma, T. and Katsuki, T. (2011) Aerobic Oxidative Kinetic Resolution of Secondary Alcohols with Naphthoxide-Bound Iron (Salan) Complex. Journal of the American Chemical Society, 133, 12937-12939. https://doi.org/10.1021/ja204426s

[14] Nogawa, M., Shimojo, M., Matsumoto, K., Okudomi, M., Nemoto, Y. and Ohta, H. (2006) Kinetic Resolution of Poly(Ethylene Glycol)-Supported Carbonates by Enzymatic Hydrolysis. Tetrahedron, 62, 7300-7306. https://doi.org/10.1016/j.tet.2006.05.020

[15] Chen, C.-S., Fujimoto, Y., Girdaukas, G. and Sih, C.J. (1982) Quantitative Analyses of Biochemical Kinetic Resolutions of Enantiomers. Journal of the American Chemical Society, 104, 7294-7299. https://doi.org/10.1021/ja00389a064

\section{Submit or recommend next manuscript to SCIRP and we will provide best service for you:}

Accepting pre-submission inquiries through Email, Facebook, LinkedIn, Twitter, etc. A wide selection of journals (inclusive of 9 subjects, more than 200 journals) Providing 24-hour high-quality service User-friendly online submission system Fair and swift peer-review system Efficient typesetting and proofreading procedure Display of the result of downloads and visits, as well as the number of cited articles Maximum dissemination of your research work

Submit your manuscript at: http://papersubmission.scirp.org/

Or contact jbnb@scirp.org 